\title{
Unemployment and mental health in the German population: the role of subjective social status
}

\author{
Marie Neubert' \\ Philipp Süssenbach ${ }^{2}$ \\ Winfried Rief ${ }^{\prime}$ \\ Frank Euteneuer ${ }^{1,3}$ \\ 'Division of Clinical Psychology and \\ Psychotherapy, Philipps University, \\ Marburg, Germany; ${ }^{2}$ Division of Social \\ and Personality Psychology, \\ Fachhochschule des Mittelstands (FHM), \\ University of Applied Sciences, Bielefeld, \\ Germany; ${ }^{3}$ Division of Clinical \\ Psychology and Psychotherapy, Medical \\ School Berlin, Berlin, Germany
}

\author{
This article was published in the following Dove Press journal: \\ Psychology Research and Behavior Management
}

\begin{abstract}
Purpose: Subjective social status (SSS) reflects individuals' perceived position in a social hierarchy. Low SSS is associated with several mental health impairments. The aim of this cross-sectional study was to examine if unemployed individuals report lower SSS in Germany (national SSS) and lower SSS in their social community (local SSS) than employed individuals. Moreover, the relationship between unemployment, SSS, and mental health was examined.
\end{abstract}

Patients and methods: 113 unemployed and 1117 employed individuals from a representative German panel provided information on their national and local SSS, their monthly income and their mental health. SSS was assessed with the German version of the MacArthur Scales. Mental health was measured using the mental component scale (MCS) of the SF-12. Results: Unemployed individuals reported significantly lower national SSS, local SSS and mental health compared to employed participants. Mediational analyses suggest that the negative effect of employment status on mental health was explained via a reduction of national SSS. Local SSS did not mediate the association of employment status and mental health.

Conclusion: Unemployment is associated with lower SSS and reduced mental health. The perceived position relative to others in the country (ie, national SSS) mediates the association between employment status and mental health.

Keywords: unemployed, perceived social position, SF-12, income, Socio-Economic Panel

\section{Introduction}

Unemployment has been identified as an important factor influencing mental health. Results of several studies and meta-analyses indicated negative effects of unemployment on psychological wellbeing. ${ }^{1-5}$ Moreover, epidemiological research has found a higher risk for common mental disorders (eg, major depression, anxiety disorders and alcohol abuse/dependence) in unemployed individuals. ${ }^{6-8}$ Importantly, depression following job loss is associated with an increased risk of continued unemployment. ${ }^{9}$ Although there are many studies that demonstrate an association between unemployment and mental health impairments, the mediating processes and mechanisms by which unemployment influences mental health are not well known. ${ }^{2,10}$ Recent studies suggest that financial strain, ${ }^{11}$ frustration of life goals, ${ }^{12}$ social support and dysfunctional health behaviors (eg, smoking, drug and medication abuse) ${ }^{13}$ may mediate the negative effect of unemployment on health.

The perception of one's social position relative to others in the social hierarchy, referred to as subjective social status (SSS), might be an additional important psychological mechanism influencing mental health in unemployed individuals. SSS has been
Correspondence: Marie Neubert Division of Clinical Psychology and Psychotherapy, Philipps University, Gutenbergstraße 18, Marburg 35032, Germany

Tel +49642I 2823765

Fax +4964212828904

Email marie.neubert@uni-marburg.de 
related to several health indicators (eg, cardiovascular risk, mortality, depression), and these associations normally persist even after adjusting for objective socioeconomic measures (OSS) such as income, education and occupation. ${ }^{14-16}$ Some findings suggest that SSS might be a more comprehensive measure of the social position since it enables a cognitive averaging of a broader range of status-related information including past and future prospects. ${ }^{15,17}$ Recent research further suggested that SSS mediates the association between OSS and health. ${ }^{18-20}$

Low SSS is associated with common mental disorders such as depression, ${ }^{21,22}$ anxiety $^{23,24}$ and substance abuse. ${ }^{25,26}$ The risk for such mental disorders is elevated among unemployed individuals. Although research on determinants of SSS suggests that employment status influences SSS and that unemployed individuals report lower neighborhood $\mathrm{SSS},{ }^{17,27,28}$ little research has been done on local and national SSS and the association of SSS with mental health in unemployed individuals. Therefore, the aim of this study was to examine if SSS in Germany (national SSS) and SSS in the social community (local SSS), as well as mental health ratings, differ between unemployed and employed individuals. We further examined the mediating role of SSS in the relationship between OSS (ie, employment status and household income) and mental health. Based on the existing literature we hypothesized that unemployed individuals report lower national and local SSS as well as lower mental health than employed individuals. We further expected that SSS mediates the links between OSS and mental health. This study extends the existing literature by focusing on national and local SSS in unemployed individuals of the German population.

\section{Materials and methods}

\section{Study sample}

Cross-sectional data for the current study were obtained from the German Socio-Economic Panel (SOEP). SOEP is a representative, longitudinal household panel study. ${ }^{29,30}$ The initial wave of the survey in 1984 included nearly 6,000 households and about 12,000 individuals. The SOEP has been improved continuously over the years concerning representativeness of the sample and quality of data collection. ${ }^{29}$ SOEP uses probability sampling to represent Germany's resident population. The statistical projection of the SOEP-Sample is updated at an annual rate to maintain a representative sample. ${ }^{31}$ In 2011, the SOEP Innovation Sample (SOEP-IS), a new subsample for innovative research questions, was established. ${ }^{32}$ The data of the present study were collected in the SOEP-IS 2016, since the measurement for SSS was implemented in survey wave 2016 for the first time. All participants were interviewed by trained interviewers between September 2016 and February 2017. The questioning took place at the participants' home. Collected data were stored anonymously on electronic devices and transferred to the German Institute of Economic Research (DIW). ${ }^{29,32}$ The SOEP team ensures high data quality by constant checking routines and institutional safeguards. For example, they run analyses to correct for selective response rates. They also train and monitor the interviewers to verify their correct work. ${ }^{31}$ More detailed information regarding study design and data collection can be found elsewhere. ${ }^{29,31,32}$ The SOEP-IS 2016 included 3049 households and was divided into four subsamples with slightly different questionnaires. A subsample of 2156 participants answered the questionnaire including national and local SSS. Out of this subsample we included all participants of working age (15-65 years) who matched our criteria for employment or unemployment status. Leading to a total sample size of 1,230 individuals. An independent committee at the DIW monitors SOEP survey ethics.

\section{Measures}

\section{Employment status}

Employment status was defined by two categories (employed and unemployed) to examine the health differences between those two groups. SOEP-IS provides detailed information on the participants' employment status, for example whether they are employed, registered unemployed, retired, doing an internship or are on maternity leave. Only persons, who were officially registered unemployed at the German Federal Employment Agency at the time of the interview, were considered as unemployed participants. The group of employed individuals only included participants, who worked by the time they were interviewed.

\section{Social status}

Objective social status (OSS) was defined by the net equivalent income (€/month). Calculations according to the Organization for Economic Cooperation and Development (OECD) modified scale took into account the size of the household and the age of all household members for consideration of household-specific needs. ${ }^{33}$

Subjective social status (SSS) was measured by German versions ${ }^{34}$ of the MacArthur Scales. ${ }^{14}$ The MacArthur scales are valid measures to assess individuals' subjective social 
standing. ${ }^{34,35}$ In this study we assessed local and national SSS. Local SSS represents the perceived social standing in one's social environment and is thus linked to proximal comparison. To assess local SSS, participants were asked to place themselves on a 10-rung ladder in comparison to their social environment. The top of the ladder represents people with the highest and the bottom those with the lowest standing in the social environment. National SSS represents one's perceived social standing in relation to people of the national population regarding traditional socioeconomic indicators. For national SSS, participants rated their own position on the social ladder in comparison to those who are the best and the worst off with respect to money, education and jobs in Germany. Higher scores indicate higher SSS.

\section{Mental health}

Self-reported mental health was assessed with the mental component summary scale (MCS) of the SF-12 health survey. $^{36}$ The MCS score (0-100) includes six items regarding vitality, social functioning, emotional role functioning and mental health (eg, "During the past month, how much of the time have you felt calm and peaceful?") with five ordered response categories from 1 (always) to 5 (never). Since the SOEP includes a specific version of the SF-12 questionnaire, an algorithm was used to compute norm values for the main scales. ${ }^{37}$ Higher scores indicate better mental health. This questionnaire was developed for large surveys. ${ }^{38}$ The MCS is a valid and reliable $(\alpha=0.76$ for the total sample) measure of mental health in epidemiological research and a useful screening tool for depression and anxiety disorders. ${ }^{39}$

\section{Statistical analysis}

Statistical analyses were carried out with IBM SPSS version 23.0 for Windows (Chicago,SPSS,Inc.) and Mplus7 (Muthén \& Muthén, 1998-2012). Missing values occurred and extreme outliers were defined as missing values (ie, values more than three interquartile ranges above the 75 th percentile). Pairwise comparisons of demographics, SSS and mental health were calculated with two-tailed $t$-tests or chi-square tests as appropriate. The associations of SSS with employment status, income and mental health were estimated using a conceptual path model with maximum likelihood estimation and 1000 bootstrap samples, adjusted for sex and age.

\section{Results}

Data were available as follows: $94.89 \%$ of the sample provided information about income, 98.9\% about local
SSS, 98.6\% about national SSS and 98.8\% regarding mental health. Table 1 presents demographic characteristics for unemployed $(\mathrm{N}=113)$ and employed individuals $(\mathrm{N}=1117)$. The sample of employed individuals included apprentices (8.68\%), self-employed (8.68\%), manual laborers (14.59\%), employees (62.31\%) and civil servants $(5.73 \%)$. Unemployed individuals reported significantly lower income than employed participants, $t_{(1165)}=17.35$, $p<0.001$.

There were significant differences between groups for national SSS, $t_{(1211)}=7.57, p<0.001$, Cohen's $d=0.81$, and local SSS, $t_{(1214)}=6.67, p<0.001$, Cohen's $d=0.72$. Unemployed individuals reported lower national SSS (employed: $M=6.01, S D=1.55$; unemployed: $M=4.61$, $S D=1.89$ ) and local SSS (employed: $M=6.57, S D=1.53$; unemployed: $M=5.31, S D=1.94$ ) than employed participants (Figure 1). Unemployed individuals reported lower mental health (employed: $M=53.81, S D=9.13$; unemployed: $M=49.58, S D=11.24), t_{(1214)}=3.78, p<0.001$, Cohen's $d=0.41$ (Figure 2).

To test the mediation effects of national SSS and local SSS on the association between employment status and mental health two conceptual path models were carried out. In the first base model we included employment status, income and mental health. Mental health was reduced in unemployed individuals $(\mathrm{B}=3.675,95 \% \mathrm{CI}$ $[1.521,6.106], p=0.002)$. This relationship was mediated by income ( $\mathrm{B}=0.715,95 \% \mathrm{CI}[0.272,1.236], p=0.003)$. Unemployed individuals reported lower income, which in turn was associated with reduced mental health.

A second model included national SSS and local SSS in addition to the variables studied in the first base model. Taking subjective social status into account, the mediational role of income between employment status and mental health was no longer significant $(\mathrm{B}=0.370,95 \%$ CI $[-0.077,0.932]$, $p=0.144$ ). Figure 3 displays the results for this model.

Table I Demographic characteristics of participants

\begin{tabular}{|l|l|l|l|}
\hline Variable & Employed & Unemployed & $p$ \\
\hline Sex, n (\%) & & & \\
Female & $557(45.28)$ & $54(4.39)$ & 0.674 \\
Male & $560(45.53)$ & $59(4.8)$ & \\
Age, mean (SD) & 42.44 & $43.58(12.97)$ & 0.382 \\
Net equivalent income in & $(13.13)$ & & \\
$€ /$ month, mean (SD) & $(1986.92$ & 1000.72 & $<0.001$ \\
\hline
\end{tabular}

Notes: $p$-values for differences derived from chi-square test (categorical variable) and $t$-tests (continuous variables). 


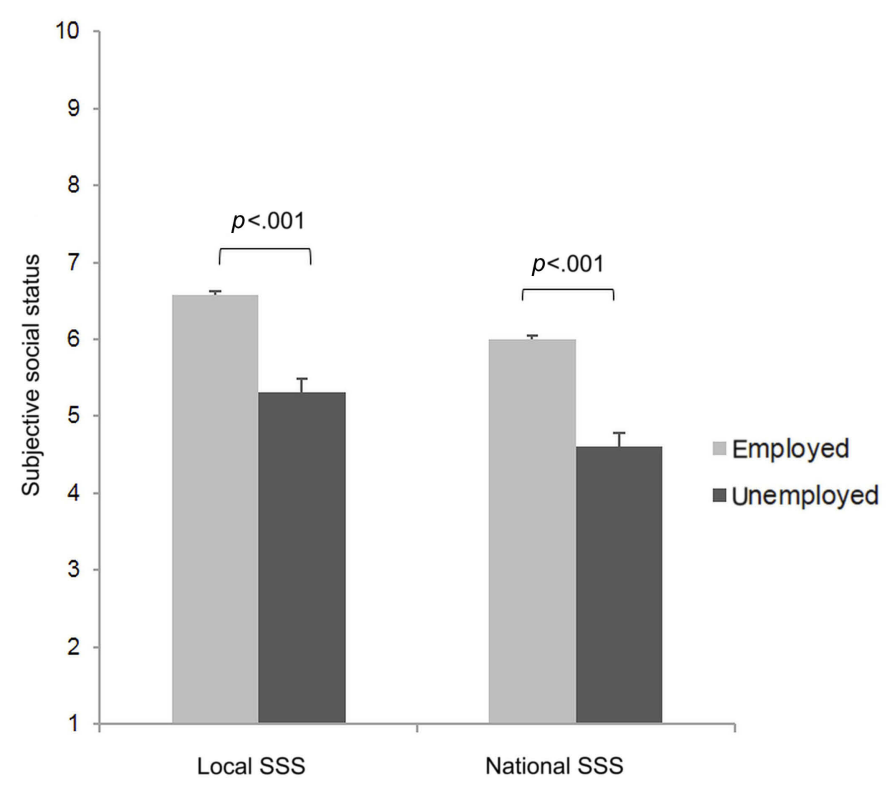

Figure I Group means and standard errors of subjective social status in the social environment (local SSS) and in Germany (national SSS) in employed and unemployed individuals.

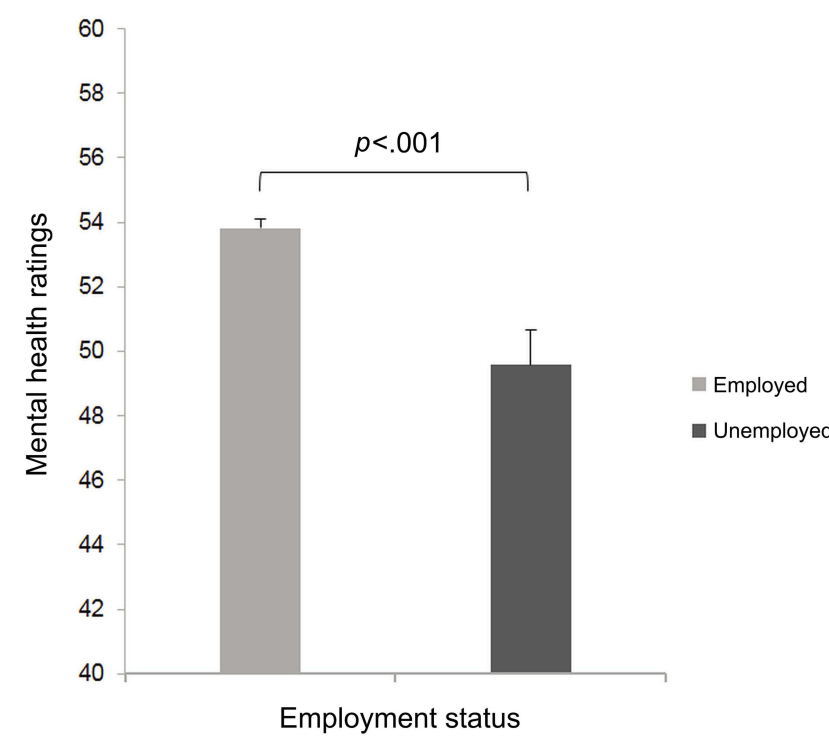

Figure 2 Group means and standard errors of norm based mental health scores for employed and unemployed individuals.

Mental health was reduced in unemployed individuals, as compared to employed individuals $(\mathrm{B}=2.906,95 \% \mathrm{CI}$ $[0.782,5.246], p=0.012)$. National SSS mediated the association of employment status with mental health $(\mathrm{B}=0.6,95 \% \mathrm{CI}$ $[0.234,1.127], p=0.01)$. Thus, unemployed individuals experienced lower national SSS, which in turn led to decreased mental health. Moreover, a second indirect effect involving national SSS was significant. The path from employment status to mental health via income and national SSS was significant $(\mathrm{B}=0.337,95 \% \mathrm{CI}[0.132,0.562], p=0.002)$. Thus, unemployment had a direct effect on national SSS and an indirect effect via income on national SSS. This second indirect effect on mental health reflects that lower income in unemployed individuals reduced their national SSS, which resulted in worse mental health. For local SSS no direct effects on mental health nor mediation effects were found.

\section{Discussion}

The aim of this study was to examine if unemployed individuals report lower SSS in Germany (national SSS) and lower SSS in their social community (local SSS) than employed individuals. Our main finding is that unemployed individuals reported lower national SSS and lower local SSS as well as poorer mental health compared to employed individuals. Moreover, we examined the mediating role of SSS and income in the relationship between employment status and mental health. National SSS but not local SSS mediated the association between employment status and mental health, in part via income.

The current study contributes to the existing literature by showing that unemployed individuals report lower national SSS and local SSS than employed individuals in Germany. Findings suggest that unemployment affects mental health via objective status (eg, income) as well as via subjective evaluation of social standing (SSS). A better understanding of the mediating mechanisms by which 


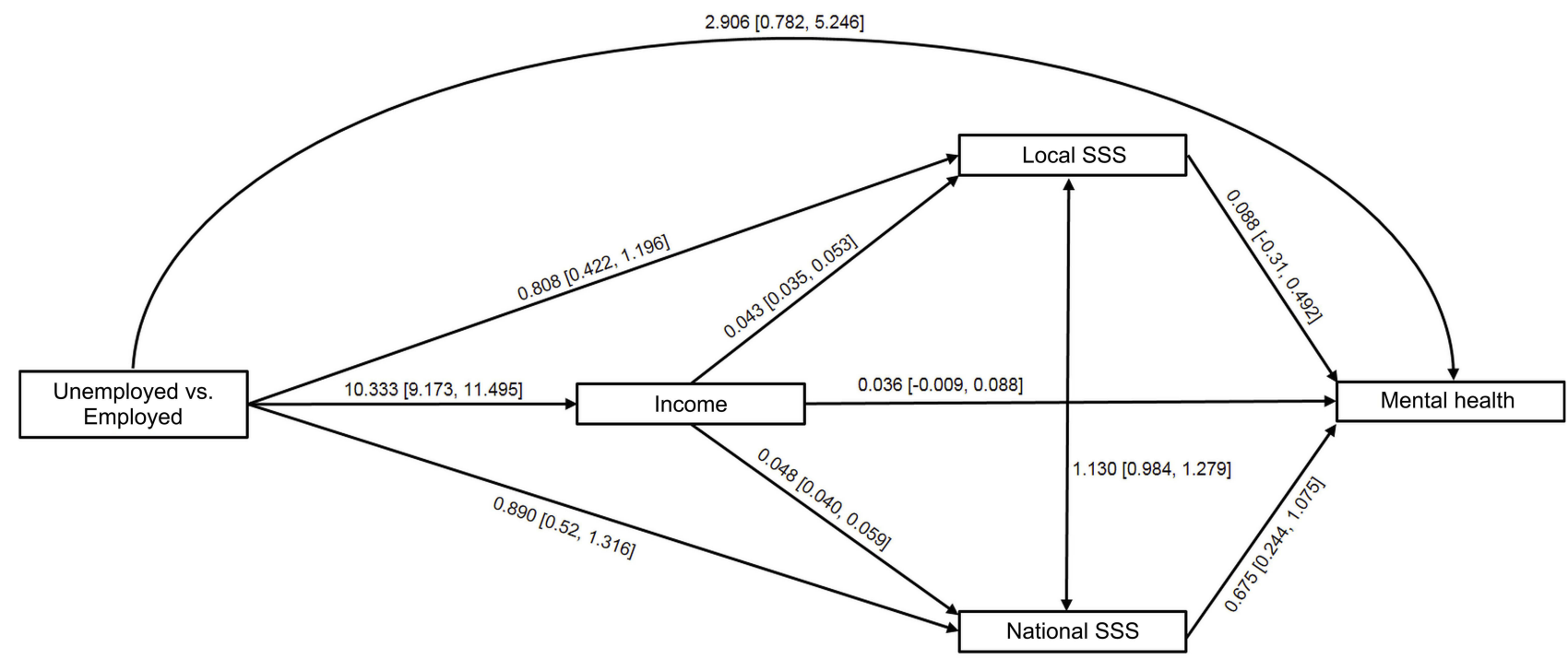

Figure 3 Path model for the association of employment status, mental health, subjective social status in the social environment (local SSS) and in Germany (national SSS) with unstandardized estimates and $95 \% \mathrm{Cls}$.

unemployment affects mental health might be helpful to improve social and psychological interventions for unemployed individuals. ${ }^{2,40}$ Professionals, who conceptualize social and psychological interventions to reduce mental health problems in unemployed individuals, might consider the potential effect of SSS. Therefore, results from studies investigating the mediating mechanisms by which SSS influences mental health could be of interest. For example, Schubert et al. $^{41}$ found in an experimental study that low SSS elevated depressive cognitions and rumination. Other studies reported that rumination next to anxiety sensitivity mediated the associations between SSS and anxiety and depressive disorders. ${ }^{23,42}$

Our results suggest that the negative effect of unemployment and lower income on mental health is explained via a reduction of national SSS. Income changes in unemployed individuals seem to be a relevant factor influencing mental health. Lower income in unemployed individuals leads to financial strain. ${ }^{43,44}$ Singh-Manoux et al. ${ }^{17}$ argued that the feeling of financial security predicts SSS by reflecting current and future material conditions. Next to this serial mediation effect of unemployment status on mental health via income and then via national SSS, we also found a mediation effect of unemployment on mental health directly via national SSS. Thus, there seems to be a direct effect of unemployment status on SSS besides the path via income. Research on determinants of SSS suggested that life satisfaction along with other determinants predicts subjective social status. ${ }^{45}$ Several studies showed a negative effect of unemployment on satisfaction of living. ${ }^{46,47}$ Therefore, changes in life satisfaction accompanying unemployment could be a possible explanation for the direct effect of unemployment on SSS. Future research should address psychological mechanisms by which unemployment influences SSS and therefore mental health to improve psychological and social interventions for unemployed individuals.

Differentiating the two facets of SSS, local SSS did not mediate the association of employment status and mental health. Although, local SSS was reduced in unemployed individuals and in individuals with lower income, there was no effect of local SSS on mental health. In contrast, prior research showed that local SSS was associated with mental health outcomes such as depressive symptoms ${ }^{48-51}$ and perceived stress. ${ }^{52,53}$ One possible explanation for the result in this study could be that unemployed individuals tend to evaluate their position using objective status indices such as income and employment status. Unemployed individuals are often confronted with the fact that they are unemployed and that they have low income. They are aware of the fact when they get monthly unemployment benefits or when they visit the department of unemployment assistance on regular terms. Thus, the national comparison could be a more permanent or salient stressor for unemployed individuals. This more salient experience of relative status might be more meaningful for unemployed individuals and therefore more likely to influence mental health. ${ }^{35}$ On the other hand one could 
argue that the area of living might explain the fact, that local SSS did not mediate the association. Unemployed individuals, who live in deprived communities, might compare themselves to people with a similar standard of living. This more similar comparison standard could be primed by the experiences they make in everyday life. ${ }^{54}$ Future research is required to examine how individuals define local SSS in comparison to national SSS, especially in unemployed individuals.

Our findings are limited by the cross-sectional design, which preclude a causal interpretation of the models presented. Moreover, we were restricted in our choice of potential mediators in the association between SSS and mental health. Recent research suggested that social contact, ${ }^{55}$ chronic negative affect, ${ }^{56}$ as well as rumination and anxiety sensitivity ${ }^{42}$ mediate the effect of SSS on mental health. Future research should consider additional mediating mechanisms. Furthermore, the generalizability of the results may be limited since the given conditions for unemployed individuals in Germany are different compared to other countries.

\section{Conclusion}

In conclusion, our findings suggest that SSS and mental health are reduced in unemployed individuals and that SSS seems to be an important psychological mechanism influencing mental health in unemployed individuals. A better understanding of how unemployment affects mental health might be helpful to improve interventions to encounter its consequences. The results of the present study suggest that targeting individuals' perception of their standing in society should be one focal point of such interventions. In consequence, public policy should try to reduce the stigma that comes from unemployment and foster ways by which unemployed individuals can enhance their perceived social standing; for example via civic engagement or volunteering.

\section{Ethical statement}

The study is based on an analysis of previously collected and publicly available data. Detailed information on ethical clearance and informed consent given by the participants can be found online (https://www.diw.de/en/soep).

\section{Acknowledgments}

An abstract of this paper was presented at the 15th International Congress of Behavioral Medicine as a conference talk with interim findings. The talk's abstract was published in "Abstracts" in the International Journal of Behavioral Medicine; 2018;25(Suppl 1):1-219; doi:10.1007/s12529-018-9740-1.

\section{Disclosure}

The authors report no conflicts of interest in this work.

\section{References}

1. Kim TJ, von Dem Knesebeck O. Perceived job insecurity, unemployment and depressive symptoms: a systematic review and meta-analysis of prospective observational studies. Int Arch Occup Environ Health. 2016;89(4):561-573. doi:10.1007/s00420-015-1107-1

2. Paul KI, Moser K. Unemployment impairs mental health: meta-analyses. $J$ Vocat Behav. 2009;74(3):264-282. doi:10.1016/j. jvb.2009.01.001

3. McKee-Ryan F, Song Z, Wanberg CR, Kinicki AJ. Psychological and physical well-being during unemployment: a meta-analytic study. $J$ Appl Psychol. 2005;90(1):53-76. doi:10.1037/0021-9010.90.1.53

4. Fergusson DM, McLeod GF, Horwood LJ. Unemployment and psychosocial outcomes to age 30: a fixed-effects regression analysis. Aust NZJ Psychiatry. 2014;48(8):735-742. doi:10.1177/0004867414525840

5. Pelzer B, Schaffrath S, Vernaleken I. Coping with unemployment: the impact of unemployment on mental health, personality, and social interaction skills. Work. 2014;48(2):289-295. doi:10.3233/WOR-131626

6. Jacobi F, Höfler M, Siegert J, et al. Twelve-month prevalence, comorbidity and correlates of mental disorders in Germany: the mental health module of the german health interview and examination survey for adults (DEGS1-MH). Int J Methods Psychiatr Res. 2014;23(3):304-319. doi:10.1002/mpr.1439

7. Alonso J, Angermeyer MC, Bernert S, et al. Prevalence of mental disorders in Europe: results from the European Study of the Epidemiology of Mental Disorders (ESEMeD) project. Acta Psychiatr Scand Suppl. 2004;109(420):21-27. doi:10.1111/j.16000047.2004.00327.x

8. Fryers T, Melzer D, Jenkins R. Social inequalities and the common mental disorders - a systematic review of the evidence. Soc Psychiatry Psychiatr Epidemiol. 2003;38(5):229-237. doi:10.1007/ s00127-003-0627-2

9. Stolove CA, Galatzer-Levy IR, Bonanno GA. Emergence of depression following job loss prospectively predicts lower rates of reemployment. Psychiatry Res. 2017;253(2016):79-83. doi:10.1016/j. psychres.2017.03.036

10. Wanberg CR. The individual experience of unemployment. Аnпи Rev Psychol. 2012;63(1):369-396. doi:10.1146/annurev-psych-120710100500

11. Tøge AG, Blekesaune M. Unemployment transitions and self-rated health in Europe: a longitudinal analysis of EU-SILC from 2008 to 2011. Soc Sci Med. 2015;143:171-178. doi:10.1016/j.socscimed.2015.08.040

12. Paul KI, Vastamäki J, Moser K. Frustration of life goals mediates the negative effect of unemployment on subjective well-being. $J$ Happiness Stud. 2016;17(2):447-462. doi:10.1007/s10902-014-9603-7

13. Perreault M, Touré EH, Perreault N, Caron J. Employment status and mental health: mediating roles of social support and coping strategies. Psychiatr Q. 2017;88(3):501-514. doi:10.1007/s11126-016-9460-0

14. Adler N, Epel ES, Castellazzo G, Ickovics JR. Relationship of subjective and objective social status with psychological and physiological functioning: preliminary data in healthy white women. Health Psychol. 2000;19(6):586-592. doi:10.1037/0278-6133.19.6.586

15. Singh-Manoux A, Marmot MG, Adler NE. Does subjective social status predict health and change in health status better than objective status? Psychosom Med. 2005;67:855-861. doi:10.1097/01. psy.0000188434.52941.a0 
16. Ostrove JM, Adler NE, Kuppermann M, Washington AE. Objective and subjective assessments of socioeconomic status and their relationship to self-rated health in an ethnically diverse sample of pregnant women. Health Psychol. 2000;19(6):613-618. doi:10.1037/ 0278-6133.19.6.613

17. Singh-Manoux A, Adler NE, Marmot MG. Subjective social status: its determinants and its association with measures of ill-health in the Whitehall II study. Soc Sci Med. 2003;56(6):1321-1333. doi:10.1016/ S0277-9536(02)00131-4

18. Demakakos P, Nazroo J, Breeze E, Marmot M. Socioeconomic status and health: the role of subjective social status. Soc Sci Med. 2008;67 (2):330-340. doi:10.1016/j.socscimed.2008.03.038

19. Roy AL, Godfrey EB, Rarick JRD. Do we know where we stand? Neighborhood relative income, subjective social status, and health Am J Community Psychol. 2016;57:448-458. doi:10.1002/ajcp.12049

20. Hoebel J, Maske UE, Zeeb H, Lampert T. Social inequalities and depressive symptoms in adults: the role of objective and subjective socioeconomic status. PLoS One. 2017;12(1):1-18. doi:10.1371/journal. pone. 0169764

21. Vidal C, Brown W, Lilly FRW. The impact of subjective and objective social status on depression in a Cohort of graduate-level students. Open J Soc Sci. 2018;6(5):287-301. doi:10.4236/jss.2018.65021

22. Zvolensky MJ, Paulus DJ, Bakhshaie J, et al. Subjective social status and anxiety and depressive symptoms and disorders among low income latinos in primary care: the role of emotion dysregulation. Cognit Ther Res. 2017;41(5):686-698. doi:10.1007/s10608-017-9844-y

23. Talavera DC, Paulus DJ, Garza M, et al. Subjective social status and rumination in relation to anxiety and depressive symptoms and psychopathology among economically disadvantaged Latinos in primary care. Am J Orthopsychiatry. 2018;88(2):169-179. doi:10.1037/ort0000223

24. Zvolensky MJ, Bakhshaie J, Garza M, et al. Anxiety sensitivity and subjective social status in relation to anxiety and depressive symptoms and disorders among Latinos in primary care. J Anxiety Disord. 2015;32:38-45. doi:10.1016/j.janxdis.2015.03.006

25. Finch KA, Ramo DE, Delucchi KL, Liu H, Prochaska JJ. Subjective social status and substance use severity in a young adult sample. Psychol Addict Behav. 2013;27(3):901-908. doi:10.1037/a0032900

26. Camelo LDV, Giatti L, Barreto SM. Subjective social status, selfrated health and tobacco smoking: brazilian Longitudinal Study of Adult Health (ELSA-Brasil). J Health Psychol. 2014;19(11):13881399. doi:10.1177/1359105313490772

27. Geiger AM, Kirschbaum C, Wolf JM. Comparison group matters for chronic stress effects of subjective social status. J Health Psychol. 2017;135910531770951. doi:10.1177/1359105317709511

28. Adler N, Singh-Manoux A, Schwartz J, Stewart J, Matthews K, Marmot MG. Social status and health: a comparison of British civil servants in Whitehall-II with European- and African-Americans in CARDIA. Soc Sci Med. 2008;66(5):1034-1045. doi:10.1016/j.socscimed.2007.11.031

29. Wagner GG, Frick JR, Schupp J. The German Socio-Economic Panel Study (SOEP) - scope, evolution and enhancements. SOEP Pap Multidiscip Panel Data Res DIW Berlin. 2007;1(127):139-169. doi:10.2139/ssrn.1028709

30. Britzke J, Schupp J SOEP wave report 2016; 2016. https://www.diw. de/documents/publikationen/73/diw_01.c.560446.de/wave_report 2016.pdf. Accessed January 11, 2018.

31. Goebel J, Grabka MM, Liebig S, et al. The German Socio-Economic Panel (SOEP). J Econ Stat. 2019;239(2):345-360. doi:10.1515/jbnst-2018-0022

32. Richter D, Schupp J. SOEP Innovation Sample (SOEP-IS) description, Structure and Documentation. SSRN Electron J. 2012. doi:10.5684/soep.is. 2014

33. OECD. WHAT ARE EQUIVALENCE SCALES?; 2009. http:// www.oecd.org/els/soc/OECD-Note-EquivalenceScales.pdf. Accessed January 11, 2018.
34. Euteneuer F, Süssenbach P, Schäfer SJ, Rief W. Subjektiver sozialer status. MacArthur-Skalen zur Erfassung des wahrgenommenen sozialen Status im sozialen Umfeld (SSS-U) und in Deutschland (SSS-D). Verhaltenstherapie. 2015;25(3):229-232. doi:10.1159/000371558

35. Cundiff JM, Smith TW, Uchino BN, Berg CA. Subjective social status: construct validity and associations with psychosocial vulnerability and self-rated health. Int J Behav Med. 2013;20(1):148-158. doi:10.1007/s12529-011-9206-1

36. Ware J, Kosinski M, Keller SD. SF-12: How to Score the SF-12 Physical and Mental Health Summary Scales. 2nd ed. Boston (MA): The Health Institute, New England Medical Center, 1995.

37. Andersen HH, Mühlbacher A, Nübling M, Schupp J, Wagner GG. Computation of standard values for physical and mental health scale scores using the SOEP version of SF-12v2. Schmollers Jahrbuch. 2007;127(1):171-182.

38. Ware J, Kosinski M, Keller SD. A 12-item short-form health survey: construction of scales and preliminary tests of reliability and validity. Med Care. 1996;34(3):220-233. doi:10.1097/00005650-19960300000003

39. Gill SC, Butterworth P, Rodgers B, Mackinnon A. Validity of the mental health component scale of the 12-item Short-Form Health Survey (MCS-12) as measure of common mental disorders in the general population. Psychiatry Res. 2007;152(1):63-71. doi:10.1016/ j.psychres.2006.11.005

40. Kim TJ, von Dem Knesebeck O. Is an insecure job better for health than having no job at all? A systematic review of studies investigating the health-related risks of both job insecurity and unemployment. BMC Public Health. 2015;15(1):1-9. doi:10.1186/ s12889-015-2313-1

41. Schubert T, Süssenbach P, Schäfer SJ, Euteneuer F. The effect of subjective social status on depressive thinking: an experimental examination. Psychiatry Res. 2016;241:22-25. doi:10.1016/j. psychres.2016.04.081

42. Zvolensky MJ, Paulus DJ, Bakhshaie J, et al. Anxiety sensitivity and rumination: transdiagnostic factors involved in the relation between subjective social status and anxiety and depressive symptoms and disorders among economically disadvantaged latinos in primary care. Am J Orthopsychiatry. 2018;88:571-581. doi:10.1037/ort0000307

43. Ervasti H, Venetoklis T. Unemployment and subjective well-being: an empirical test of deprivation theory, incentive paradigm and financial strain approach. Acta Sociol. 2010;53(2):119-139. doi:10.1177/ 0001699310365624

44. Huijts T, Reeves A, Mckee M, Stuckler D. The impacts of job loss and job recovery on self-rated health: testing the mediating role of financial strain and income. Eur J Public Health. 2015;25(5):801806. doi:10.1093/eurpub/ckv108

45. Lundberg J, Kristenson M. Is subjective status influenced by psychosocial factors? Soc Indic Res. 2008;89(3):375-390. doi:10.1007/ s11205-008-9238-3

46. Chen W-H, Hou F. The effect of unemployment on life satisfaction : a cross-national comparison between Canada, Germany, the United Kingdom and the United States. Appl Res Qual Life. 2018. doi:10.1007/s11482-018-9638-8

47. Lipps O, Oesch D. The working class left behind? The class gap in life satisfaction in Germany and Switzerland over the last decades. European Soc. 2018:1-23. doi:10.1080/14616696.2018.1448106

48. Euteneuer F, Mills PJ, Rief W, Ziegler MG, Dimsdale JE. Subjective social status predicts in vivo responsiveness of $\beta$-adrenergic receptors. Health Psychol. 2012;31(4):525-529. doi:10.1037/a0025990

49. Kraus MW, Piff PK, Mendoza-Denton R, Rheinschmidt ML, Keltner D. Social class, solipsism, and contextualism: how the rich are different from the poor. Psychol Rev. 2012;119(3):546-572. doi: $10.1037 / \mathrm{a} 0028756$ 
50. Michelson N, Riis JL, Johnson SB. Subjective social status and psychological distress in mothers of young children. Matern Child Health J. 2016;20(10):2019-2029. doi:10.1007/s10995-016-2027-8

51. Diaz OV, Guendelman S, Kuppermann M. Subjective social status and depression symptoms: a prospective Study of women with noncancerous pelvic problems. Women's Health Issues. 2014;24(6):649655. doi:10.1016/j.whi.2014.07.003

52. Garey L, Reitzel LR, Kendzor DE, Businelle MS. The potential explanatory role of perceived stress in associations between subjective social status and health-related quality of life among homeless smokers. Behav Modif. 2016;40(1-2):303-324. doi:10.1177/0145445515612396

53. Fleuriet KJ, Sunil TS. Subjective social status, mental and psychosocial health, and birth weight differences in Mexican-American and Mexican immigrant women. J Immigr Minor Health. 2015;17 (6):1781-1790. doi:10.1007/s10903-015-0178-0
54. Hoebel J, Lampert T. Subjective social status and health: multidisciplinary explanations and methodological challenges. $J$ Health Psychol. 2018;135910531880080. doi:10.1177/1359105318800804

55. Rubin M, Evans O, Wilkinson RB. A longitudinal study of the relations among university students' subjective social status, social contact with university friends, and mental health and well-being. J Soc Clin Psychol. 2016;35(9):722-737. doi:10.1521/jscp.2016.35.9.722

56. Kraus MW, Adler N, Chen T-WD. Is the association of subjective SES and self-rated health confounded by negative mood? An experimental approach. Health Psychol. 2013;32(2):138-145. doi:10.1037/ a0027343

\section{Publish your work in this journal}

Psychology Research and Behavior Management is an international, peer-reviewed, open access journal focusing on the science of psychology and its application in behavior management to develop improved outcomes in the clinical, educational, sports and business arenas. Specific topics covered in the journal include: Neuroscience, memory and decision making; Behavior modification and management; Clinical applications; Business and sports performance management; Socia and developmental studies; Animal studies. The manuscript management system is completely online and includes a very quick and fair peer-review system, which is all easy to use. Visit http://www. dovepress.com/testimonials.php to read real quotes from published authors. 